\title{
Enhancing College Students’ Autonomous Oral English Learning in the Network Environment
}

\author{
Chunmei Jiang \\ College English Teaching Department \\ Zaozhuang University \\ Zaozhuang, China
}

\begin{abstract}
College students' oral English proficiency and autonomous learning ability are emphasized as two extremely significant objectives of college English education. The popularity of network terminals like computers and mobile phones has revolutionized the way for college students to learn oral English. Research on English autonomous learning for college students in the network environment has gradually increased in China recent years, but they mainly take English as a comprehensive ability, few of them focusing on the autonomous learning of the individual language skills like speaking. This study investigates the present situation of non-English Major students' autonomous oral English learning in the network environment. Analysis of data collected by the questionnaire indicates that students' autonomous oral English learning ability still needs great improvement, motivation needs to be promoted, guidance and monitoring on the learning process is required and application of some meta-cognitive strategies should be strengthened. Optimizational suggestions are put forward in the end in the hope of providing some references for other autonomous learners, English teachers, schools and researchers.
\end{abstract}

Keywords-oral English; autonomous learning; network environment

\section{INTRODUCTION}

The explosive growth of information in the Internet Age has posed a fatal threat to the once-and -for-all type of education which can hardly satisfy the requirements of people's present life and study, endowing education with sustainable and personalized characteristics. Concepts like "life-long learning" and "learning society" have gained increasing popularity beyond campus. Contemporary education, higher education in particular, is making dramatic changes accordingly to conform to the trend of autonomous learning. The Ministry of Education in China released College English Teaching Guide in 2016, emphasizing College students' oral English proficiency and autonomous learning ability as two extremely significant objectives of college English education. College English teachers emphasize students' after-class practice as an important means of improving oral English, because of the huge class capacity, thus inadequate practice in class. It is frequently observed that in class teachers instruct students in some methods and strategies of oral English learning and practice, whereas the specific practice is accomplished by students themselves after class, resulting in various individualized autonomous oral English learning.
The popularity of mobile phone as a network terminal has revolutionized the way for college students to learn oral English. Learning English is no longer confined to the classroom and study room, instead it can take place in the dormitory, on the road, even anytime and anywhere. Students reading English or reciting English words by downloaded application software on their mobile phones can be seen everywhere on campus. As an instrument for autonomous learning, the network has infiltrated the study life of college students. Learning English by means of the Internet not only enables students to experience the convenience of individualized learning but also helps cultivate their autonomous learning ability, laying a solid foundation for their future development. Therefore, research on college students' learning oral English autonomously in the network environment should be conducted, which is meaningful for the whole oral English autonomous learning group and will reveal some inspirations for English teachers in cultivating students' autonomous learning ability.

\section{RESEARCH ON ENGLISH AUTONOMOUS LEARNING AND THE INTERNET IN CHINA}

Internet has played a very important role as a means of English teaching and learning and attracted the attention of related teaching research. Consequently, research on English autonomous learning for college students in the network environment has gradually increased in China recent years, which can be mainly classified into three categories based on the past four years' related literature in CNKI, a widely used online literature library in China.

The first category studies the positive effect of the network environment on the cultivation of college students' English autonomous learning ability. Through the experiment of autonomous learning in the network environment, Shuhui Piao (2014) found that the teaching guidance model of autonomous learning based on computer network is more effective than the traditional classroom teaching mode in improving students' autonomous learning ability, because the online English learning impels students to learn actively, make study plans, exploit strategies and make reflections. She also pointed out that autonomous learning online cannot be completely divorced from teachers' guidance. Yaling Sun (2014) analyzed the role of network environment in promoting students' learning motivation and interest, and the role of the construction of 
network resource platform in cultivating students' learning strategies and students' autonomous learning model. Yan Zhang (2015) proposed that autonomous learning in the network environment can help students get rid of their dependence on teachers and adjust their own learning independently, thus significantly improving students' autonomous learning ability and learning achievement.

The second category discusses the problems and strategies of constructing the teaching mode of college students' English autonomous learning, which is a summary of the practice of college English teaching in cultivating students' English autonomous learning ability. Shuiling Chen (2014) analyzed the situation of college freshmen's online autonomous English learning through investigation and teaching practice respectively, summarized the problems students encounter in the process and put forward some suggestions for the construction of autonomous English learning model under the network platform. Based on the investigation of the mixed teaching mode of "classroom teaching plus autonomous learning online", Tanxiao Liu (2014) pointed out the inefficient and time-consuming phenomenon of the web-based self-study mode and suggested taking English for Specific Purposes as the teaching content. Shujun Liu (2014) analyzed the inadaptability of college students' autonomous learning in multimedia network learning environment and learning mode. The adaptability of students to network teaching environment is caused by inconvenient access to network teaching resources, diversity of resources and so on. The inadaptability of students' learning style is caused by the confusion of learning strategies. Min Guo (2015) put forward the construction steps of the teaching model of English autonomous learning under the network environment and shed light on the financial, institutional and teacher support for the construction of this model.

The third category focuses on the ability and strategy of English autonomous learning from the perspective of students. Yan Chen (2014) conducted an investigation on the autonomous learning of spoken English among high school students, finding that though high school students are very interested in oral English learning, they lack careful planning and strong goals. The study involves autonomous learning of spoken English but not the autonomous learning in the network environment. Caixia Huang and Ting Yu (2016) investigated students' learning efficiency, their satisfaction with e-learning and their hopes and suggestions to the school's English autonomous learning platform.

These studies have enriched research on English autonomous learning in the network environment, but most studies take English as a comprehensive ability, few of them focusing on the autonomous learning of the individual language skills, like listening, speaking, reading or writing. This study combines autonomous learning and oral English learning, which is rarely involved in previous studies. By investigating students' autonomous oral English learning ability in the network environment, discussing their present autonomous learning situation, this study offers some optimization suggestions, which is believed to enrich research on English autonomous learning from the learners' perspective and provide some enlightenment to the study of the teaching mode of English autonomous learning.

\section{The Status QuO OF StUdents' Autonomous ORAL ENGLISH LEARNING IN THE NETWORK ENVIRONMENT}

Questionnaire is adopted in order to get a clear picture of the status quo of students' autonomous oral English learning through network terminals (including various electronic devices such as mobile phones and computers). With some experience in college English learning after a semester's English class, more free time than students of other grades and easy access to the Internet, Non-English major freshmen are chosen as the subjects. The questionnaire is divided into three parts. The first part is used to understand whether college students learn oral English and realize the importance of oral English. The second part is to investigate the specific tools of college students' autonomous learning of oral English after class: network tool and non-network tool. The third part is designed to investigate the present situation of students' autonomous oral English learning in the network environment, mainly including learning ability, beliefs, motivation and affecting factors of learning effect.

Data collected by the first part of the questionnaire shows that out of 300 participants, only 220 students learn oral English autonomously after class even though 281 students realize the significance of oral English learning. It is clear from data of the second part that only 15 students never use Internet to learn oral English while the rest learn oral English with and without network. Among means of learning oral English without network, the most frequently used one is to read aloud the textbook. Reading and imitating oral English in English videos through apps on mobile phones is the most popular way of learning oral English in the network environment. Analysis of data of the third part suggests that among the 205 students learning oral English autonomously in the network environment, less than $40 \%$ set learning goals, make learning plans and can control their learning time well and just half of them can choose proper learning materials. In terms of regulating learning process, only half respondents imitate and repeat learning materials, $5 \%$ of them take notes while learning, $27 \%$ chat with other learners online and half of them believe that they are independent in their autonomous learning and they can control their emotions while learning. Speaking of evaluation, half respondents argue that they evaluate and reflect on their learning process and effects and are willing to learn from students who have successful experience of learning English online and that autonomous learning in the network environment has improves the efficiency of their oral English learning. Students' network autonomous oral English learning ability still needs immense improvement. With regard to beliefs of autonomous oral English learning in the network environment, most students consider online learning as a super way of learning, but no more than half express their willingness to learn free learning materials provided by school. Concerning motivation, $65 \%$ state that they want to improve their oral English proficiency, half of them hold that Internet increases their learning interest, half express that they have to finish assignments and some want to pass some oral English exams. As for affecting factors of learning effect, students 
insist that learners' will and capability is the most important factor, meanwhile, external factors like proper online learning materials, others' suggestions and supervision serve as important factors as well.

To conclude, most students realize the significance of oral English learning, but quite a lot of them put no effort into it; students learn oral English autonomously with and without the help of Internet, two means of learning being the most popular, reading aloud the textbook and imitating oral English in English videos through apps on mobile phones; students' autonomous learning ability still needs great improvement; the majority of students approve learn oral English autonomously in the network environment; students want to improve their oral English and Internet makes oral English learning more interesting; learning effects mainly depend on learners' will and capability while good choice of learning material and others' suggestions can affect learning effects to a large extent.

\section{COUNTERMEASURES TO IMPROVE AUTONOMOUS ORAL ENGLISH LEARNING IN THE NETWORK ENVIRONMENT}

The findings indicate that students don't have strong motivation to learn oral English autonomously, let alone in the network environment. Without strong learning motivation, however interesting the learning resources are on the Internet, students won't take oral English learning seriously, thus students' motivation must be promoted. Besides, it is concluded that students' autonomous learning ability still needs to be improved, unable to do well in planning, regulating and evaluating their autonomous learning, which directly hinder students from obtaining satisfactory learning effects. Therefore, the training of autonomous learning strategy must be carried out. In addition, many students fail to choose proper learning materials, resulting in loss of interest and confidence and slowing down the pace of progress. As a result, learning resources must be carefully chosen. To tackle these problems, suggestions are provided in the following part.

\section{A. Promoting Students' Oral English Learning Motivation}

The findings of the study show that awareness of the importance of oral English among non-English majors doesn't necessarily motivate students to learn oral English autonomously. Many students lack motivation to learn because they are not required to take an oral English examination. To solve this problem and to test students' English application ability, the national largest scale College English Test in China sees big changes in its question type and report card. Including students' grade of oral English test in the report card is the latest change which surely promotes many students to take oral English learning more seriously. Other than efforts from the authorities, teachers play an indispensable role in promoting students' oral English learning motivation. It is highly suggested that they create a pleasant and easy learning environment to motivate students' desire to speak in English. What's more, the whole school should work together to establish an excellent oral English learning campus where students feel normal, comfortable and fashionable to speak English, which will definitely boost students' enthusiasm of autonomous oral English learning.

\section{B. Advancing Students' Autonomous Learning Strategies in Spoken English}

Research findings show that students are unable to make good use of autonomous learning strategies. Consequently, the training of autonomous learning strategy should be the key step for enhancing students' autonomous learning ability. After years of English learning, most students are well aware of and good at using many English learning strategies, however, their autonomous learning ability is far from satisfactory, which means that cultivation of students' meta-cognitive strategies is the core of improving English autonomous learning ability. Firstly, English teachers introduce the strategies of autonomous learning to students. Secondly, steps of autonomous learning can be properly rehearsed in class. Teachers are highly recommended to reserve appropriate time for students to do autonomous learning on the network and provide timely guidance when students practice strategies of autonomous learning, improving the efficiency of autonomous learning. Thirdly, learning contents needed in the classroom can be made into micro class videos, so that students can further drill and review oral lessons after class, gradually forming the habit and ability to learn independently.

\section{Developing Free Network Resources for Autonomous Oral English Learning}

Campus network, indispensable for students' study and life, if fully developed and used, can serve as a platform for oral English learning and provide convenient resources for English classroom teaching. The school is suggested to establish free campus network English learning resource library where teachers can upload the spoken language learning content of English class to the platform together with some relevant interesting oral English learning materials and students can preview and review these contents and share resources on the platform as well. Apart from a resource library, an oral English interactive zone is strongly recommended to be built on the campus network as well. Rich and colorful forms of interaction can be designed in the zone, for instance, theme-based exchange community, daily talk, speech, story-telling, etc.. Students' oral recordings saved on the platform are of great benefit to both students and teachers. Students can evaluate their own speaking, offer comments to others' speaking and see their progress after learning some time, while teachers can provide follow-up supervision to students on the platform.

\section{CONCLUSION}

Nowadays, the importance of oral English ability is selfevident, and evaluation of oral English ability has received unprecedented attention. Since December 2016, the CET-4 and CET- 6 oral test scores have been included in the transcripts along with the written ones. In the same year, the China Foreign Language Assessment Center solemnly released the International Talent English Test which focuses on English communication skills through various typical tasks of oral and written communication. Passing these oral proficiency tests will undoubtedly increase the competitiveness of non-English majors in the fierce job market. However, the results of this study show that the oral English ability and autonomous learning of non-English majors are not as optimistic as 
expected. Changing this situation requires the cooperation of students, teachers and schools. Students learn to be responsible for their own learning, making the most of learning materials online, teachers stimulate students' interest in oral English learning and teach them learning strategies, meanwhile, schools create an environment for oral English practice and use with the help of Internet. In the end, students can enjoy learning oral English autonomously with appropriate learning materials and methods, seize every opportunity to practice and use English, thus improve their oral English proficiency and become national talents and international talents.

\section{ACKNOWLEDGMENT}

Many thanks are given to all the respondents of the questionnaire for their time and efforts.

\section{REFERENCES}

[1] Shuhui Piao, "An empirical study on web-based teaching model and English autonomous learning," Chinese Journal of Education, vol. 1, pp. 25-26, 2014.

[2] Yaling Sun, "The cultivation of college students' English autonomous learning ability under the modern network platform," Journal of Hubei Correspondence University, vol. 11, pp. 153-154, 2014.

[3] Yan Zhang, "An empirical study on the cultivation of college students' English autonomous learning ability in multimedia network environment," Journal of Lanzhou Institute of Education, vol. 31, pp. 111-115, 2015.

[4] Shuiling Chen, "A study of college students' autonomous English learning under the network environment," Journal of Chongqing Institute of Science and Technology (Social Sciences Edition), vol. 12, pp. 158-160, 2014.

[5] Tanxiao Liu, "A study on the present situation of college students' autonomous English learning under the network environment," Journal of Changsha University of Technology (Social Sciences Edition), vol. 15, pp. 130-131, 2014..

[6] Shujun Liu, "A study on the adaptability of college students' English autonomous learning in multimedia network environment," Shandong Foreign Language Teaching Journal, vol. 4, pp. 66-71, 2014.

[7] Min Guo, "The way and guarantee of the construction of college students' English autonomous learning model---from the perspective of the network environment," Frontier, vol. 4, pp. 117-119, 2015.

[8] Yan Chen, "A study of high school students' autonomy in oral English learning," Chengdu: Sichuan Normal University, 2014.

[9] Caixia Huang \& Ting Yu, "An Investigation on autonomous English learning in the network environment from students' perspective," Examination and Evaluation (College English Teaching and Research Edition), vol. 6, pp. 60-64, 2015. 